\title{
Microalbuminuria in Subjects With COPD: Relationship to the New Version of Global Initiative for Chronic Obstructive Lung Disease Staging
}

\author{
Fulsen Bozkus MD, Nursel Dikmen MD, and Anil Samur PhD
}

\begin{abstract}
BACKGROUND: Microalbuminuria, used as a marker of endothelial dysfunction, is a predictor of mortality for any reason and of cardiovascular events. Recent research on the management of COPD has focused more on comorbidities, including cardiovascular events. The objective of this study was to investigate the incidence of microalbuminuria and whether it is associated with physiological and clinical features in a subject group that was classified in line with the new version of the Global Initiative for Chronic Obstructive Lung Disease stages. METHODS: The study included 105 stable subjects with mild to very severe COPD. The urinary albumin/creatinine ratio was calculated using a previously defined formula. The presence of microalbuminuria was accepted as a urinary albumin/creatinine ratio $\geq 20$ in males and $\geq 30$ in females. RESULTS: Urinary albumin/creatinine ratios were significantly higher in subjects grouped as having more symptoms and high future risk than in those with fewer symptoms and low future risk. In addition, significant differences were observed when the subjects were grouped based on $\mathrm{P}_{\mathrm{aO}_{2}}(\leq 65 \mathrm{~mm} \mathrm{Hg}$ vs $>65 \mathrm{~mm} \mathrm{Hg}), \mathrm{P}_{\mathrm{aCO}_{2}}(\leq 41 \mathrm{~mm} \mathrm{Hg}$ vs $>41 \mathrm{~mm} \mathrm{Hg})$, arterial oxygen saturation $(\leq 92 \%$ vs $>92 \%)$, and median split C-reactive protein $(\leq 4.6 \mathrm{mg} / \mathrm{L}$ vs $>4.6 \mathrm{mg} / \mathrm{L})$. Pearson correlation analysis revealed that the urinary albumin/creatinine ratio was significantly inversely correlated with percentof-predicted $\mathrm{FEV}_{1}(\mathrm{r}=-0.56, P=.001)$, percent-of-predicted $\mathrm{S}_{\mathrm{aO}_{2}}(\mathrm{r}=-0.48, P=.001)$, and $\mathrm{P}_{\mathrm{aO}_{2}}$ $(\mathrm{r}=\mathbf{0 . 6 0}, P=.001)$. A positive correlation was also found between urinary albumin/creatinine ratio and COPD assessment test scores $(r=0.53, P=.001)$. CONCLUSIONS: The results of this study indicate a strong relationship between microalbuminuria and cardiovascular events in subjects with COPD, particularly in subjects with more symptoms and high future risk. Therefore, microalbuminuria should be regularly monitored in this subgroup of subjects with COPD for risk of cardiovascular morbidity or mortality. Key words: COPD; microalbuminuria; severity of illness; scoring system. [Respir Care 2017;62(3):307-314. (C) 2017 Daedalus Enterprises]
\end{abstract}

\section{Introduction}

COPD is an important cause of morbidity and mortality throughout the world. The mortality rate of COPD is increasing, and this disease is estimated to become the third leading cause of death worldwide by $2020 .{ }^{1}$ The complex-

\footnotetext{
Dr Bozkus is affiliated with the Department of Chest Diseases, Faculty of Medicine, Kahramanmaras Sutcu Imam University, Kahramanmaras, Turkey. Dr Dikmen is affiliated with the Department of Chest Diseases, Kahramanmaras Necıp Fazıl State Hospital, Kahramanmaras, Turkey. Dr Samur is affiliated with the Department of Biostatistics, Faculty of Medicine, Akdenız University, Kahramanmaras, Turkey.
}

The authors have disclosed no conflicts of interest. ity of COPD makes a comprehensive evaluation necessary for its management.

COPD is a heterogenic disease with both pulmonary and extrapulmonary symptoms characterized by long-term poor air flow. In particular, cardiovascular disease remains one of the leading causes of mortality and morbidity in subjects with COPD, independent of the well-recognized risk factors, including age, sex, and smoking status. ${ }^{2}$

\footnotetext{
Correspondence: Fulsen Bozkus MD, Faculty of Medicine, Sutcu Imam University, Avsar Campus, 46100 Kahramanmaras, Turkey. E-mail: fulsenbatmaz@gmail.com.
}

DOI: $10.4187 /$ respcare. 05168 


\section{Microalbuminuria and GOLD Stage in Subjects With COPD}

Microalbuminuria is one of the precise indicators of cardiovascular risk. ${ }^{3,4} \mathrm{~A}$ consistent association has been shown between the presence of microalbuminuria and poor cardiovascular outcomes in subjects with hypertension and diabetes mellitus and, most importantly, in the general population. ${ }^{5,6}$ Studies conducted on the epidemiology of microalbuminuria have reported a close association between vascular disease and systemic endothelial dysfunction and have also suggested glomerular endothelial dysfunction in microalbuminuria. ${ }^{7}$ In one study, lower $\mathrm{FEV}_{1}$ and severity of emphysema have been shown to be correlated with endothelial dysfunction. ${ }^{8}$ It has been demonstrated that microalbuminuria increases in worsening periods of COPD, suggesting an association with increased glomerular filtration, resulting in protein leakage because of increased hypoxemia during COPD episodes. ${ }^{9}$

There have only been a limited number of studies in the literature reporting a higher incidence of microalbuminuria in subjects with COPD compared with age-matched controls who have a smoking pack-year value $>10$, with no comorbidities such as hypertension, diabetes mellitus, renal disease, cardiovascular disease, or malignancy in both groups. ${ }^{9-11}$ However, to the best of our knowledge, there is still no study investigating the association of microalbuminuria with COPD assessment test scores and the risk of exacerbation based on the new version of the Global Initiative for Chronic Obstructive Lung Disease (GOLD) stages. ${ }^{12}$ Therefore, in this study, we aimed to investigate the association between microalbuminuria and the new version of GOLD stages and to evaluate the clinical features that may predict cardiovascular risk in subjects with COPD.

\section{Methods}

\section{Study Population and Study Design}

The study was approved by the local ethics committee of Sutcu Imam University, and all participants gave written consent. A total of 105 subjects with COPD with a wide range of air-flow limitation from Necip Fazıl State Hospital were enrolled in the study. The diagnosis of COPD was confirmed with the GOLD 2011 guidelines. The disease was classified in line with the new version of GOLD staging (classes A-D). ${ }^{12}$ GOLD guidelines recommend the COPD assessment test or the Modified Medical Research Council dyspnea scale in evaluation of the symptoms. ${ }^{13}$ The COPD assessment test comprises 8 items scored from 0 to 5 points, including the severity of cough, phlegm, chest tightness, dyspnea, capacity for activities and exercise, confidence, sleep quality, and energy levels, ${ }^{14}$ whereas the Modified Medical Research Council dyspnea scale is a quantitative tool that evaluates only breathlessness. In this study, the COPD assessment test was applied through face-

\section{QUICK LOOK}

\section{Current knowledge}

COPD is a preventable and treatable disease with some significant extrapulmonary effects that could be of interest in terms of COPD management. Cardiovascular diseases are a major cause of mortality in COPD, particularly in patients with mild to moderate severity. Recent studies have demonstrated that the urine albu$\mathrm{min} /$ creatinine ratio can be used for the prediction of cardiovascular events. Therefore, this ratio may be of importance to identify patients with COPD who are at high risk of developing future cardiovascular events.

\section{What this paper contributes to our knowledge}

The results of this study suggest that, urinary albumin/creatinine ratio is an important noninvasive method to predict cardiovascular events in COPD subgroups, and a strong correlation was observed between microalbuminuria and Global Initiative for Chronic Obstructive Lung Disease categories. Therefore, it should be kept in mind in the management of treatment that COPD subjects with more frequent exacerbating episodes and more symptoms have a higher cardiovascular risk.

to-face interviews by a pulmonary specialist. The subjects with COPD were categorized as A, B, C, and D using a combination of the COPD assessment test symptom evaluation test and the risk for exacerbation, which was determined by the exacerbation history within the last year and the spirometric classification of air-flow limitation by the GOLD grade, which is categorized by percent-of-predicted $\mathrm{FEV}_{1}$. Category A included subjects a with low risk and fewer symptoms; B included those with low risk and more symptoms; $C$ included those with high risk and fewer symptoms; and D included those with high risk and more symptoms. The management strategy was determined in accordance with this classification.

Smoking history was determined by pack-years, which were calculated by multiplying the number of packs of cigarettes smoked per day by the number of years the person had smoked. The questionnaire was administered through a personal interview with a specific enquiry about the history of smoking, current smoking status, and packyears of smoking. All subjects were current or ex-smokers with a smoking history of $\geq 10$ pack-years. The study included subjects with COPD in the stable period between 30 and 74 y old who had no previous diagnosis of cerebrovascular disease, ischemic heart disease, or peripheral arterial disease and no clinical symptoms of these diseases and had not been treated for these diseases; nor was there 


\section{Microalbuminuria and GOLD Stage in Subjects With COPD}

a diagnosis of known renal or liver diseases or malignancies.

Subjects with a history of the presence of macroalbuminuria (urinary albumin/creatinine ratio $\geq 300 \mathrm{mg} / \mathrm{g}$ ) or previously diagnosed with diabetes mellitus; myocardial infarction; severe congestive cardiac failure; angina pectoris; electrocardiographic ST-T alterations suggesting ischemic heart disease; left bundle branch block and arrhythmias; other respiratory diseases, including obstructive sleep apnea, asthma, and interstitial lung disease; acute infections; and comorbidities, such as severe hepatic failure and malignancy were excluded from the study.

\section{Clinical Variables}

A detailed medical history and findings on physical examination were recorded for each subject. Weight and height were measured, the body mass index value was calculated, and spirometry was carried out in line with international guidelines (American Thoracic Society/European Respiratory Society). ${ }^{15}$ Arterial blood gases were measured in the samples collected by direct arterial puncture, in the morning after sitting at rest for $15 \mathrm{~min}$ and breathing room air for $\geq 45 \mathrm{~min}$.

\section{Laboratory Methods}

Following an overnight fast of $12 \mathrm{~h}$, venous blood samples were collected from the antecubital vein to analyze serum levels of C-reactive protein, creatinine, and urea. The measurements of creatinine and albumin levels and estimation of albumin excretion rates in urine were carried out according to methods described previously. Spot midstream urine was obtained in the morning from the subjects who had not done any vigorous exercise in the last $48 \mathrm{~h}$. The urinary levels of albumin and creatinine were studied from the urine specimens using an immunoturbidimetric method. Normoalbuminuria was defined as a urine albumin/creatinine ratio of $0-20 \mathrm{mg} / \mathrm{g}$ for males and $0-30 \mathrm{mg} / \mathrm{g}$ for females, whereas microalbuminuria was accepted as urinary albumin/creatinine ratio $>20 \mathrm{mg} / \mathrm{g}$ for males and urinary albumin/creatinine ratio $>30 \mathrm{mg} / \mathrm{g}$ for females.

\section{Statistical Analysis}

The subject characteristics are expressed as mean \pm SD or $n(\%)$. Numerical data were tested for normality, and then the Kruskal-Wallis test and Mann-Whitney U test were applied for comparison of the groups. Multivariate logistic regression analysis was performed to assess the risk factors for urinary albumin/creatinine ratio in COPD. Spearman's correlation coefficients (r) were used to assess the correlations between continuous variables (r). All sta-
Table 1. Characteristics of the Study Population

\begin{tabular}{|c|c|}
\hline Characteristics & Values \\
\hline Male/female sex, $n(\%)$ & $94 / 11(89.5 / 10.5)$ \\
\hline Age, mean \pm SD y & $56.99 \pm 11.671$ \\
\hline Smoking, mean \pm SD packs $/ y$ & $32.67 \pm 11.52$ \\
\hline $\mathrm{BMI}$, mean $\pm \mathrm{SD} \mathrm{kg} / \mathrm{m}^{2}$ & $25.74 \pm 3.19$ \\
\hline \multicolumn{2}{|l|}{ GOLD subgroups, $n(\%)$} \\
\hline A & $29(27.6)$ \\
\hline B & $26(24.8)$ \\
\hline $\mathrm{C}$ & $12(11.4)$ \\
\hline $\mathrm{D}$ & $38(36.2)$ \\
\hline \multicolumn{2}{|l|}{$\%$ predicted $\mathrm{FEV}_{1}, n(\%)$} \\
\hline$\geq 80 \%$ & $12(11.4)$ \\
\hline $50-80 \%$ & $57(54.3)$ \\
\hline $50-30 \%$ & $26(24.8)$ \\
\hline$<30 \%$ & $10(9.5)$ \\
\hline \multicolumn{2}{|l|}{ Mean CAT score, $n(\%)$} \\
\hline$<10$ & $41(39)$ \\
\hline$\geq 10$ & $64(61)$ \\
\hline \multicolumn{2}{|l|}{ Exacerbations (total), $n(\%)$} \\
\hline $0-1$ & $55(52.4)$ \\
\hline$\geq 2$ & $50(47.6)$ \\
\hline C-reactive protein, mean $\pm \mathrm{SD} \mathrm{mg} / \mathrm{L}$ & $5.53 \pm 3.06$ \\
\hline $\mathrm{P}_{\mathrm{aO}_{2}}$, mean $\pm \mathrm{SD} \mathrm{mm} \mathrm{Hg}$ & $66.26 \pm 9.8$ \\
\hline $\mathrm{P}_{\mathrm{aCO}_{2}}$, mean $\pm \mathrm{SD} \mathrm{mm} \mathrm{Hg}$ & $39.76 \pm 6.56$ \\
\hline $\mathrm{UACR}$, mean $\pm \mathrm{SD}$ & $22.43 \pm 7.47$ \\
\hline Presence of MAB, $n(\%)$ & $57(54.3)$ \\
\hline $\begin{array}{l}\text { BMI }=\text { body mass index } \\
\text { GOLD = Global Initiative for Chronic Obstructiv } \\
\text { CAT }=\text { COPD assessment test } \\
\text { UACR }=\text { urinary albumin/creatine ratio } \\
\text { MAB }=\text { microalbuminuria }\end{array}$ & \\
\hline
\end{tabular}

tistical analyses were performed using SPSS for Windows 18.0 (SPSS, Chicago, Illinois) software. The level of statistical significance was set at $P<.05$.

\section{Results}

The study included a total of 105 subjects who met the selection criteria. Of these subjects, $29(27.6 \%)$ were in the category GOLD A, 26 (24.8\%) GOLD B, 12 (11.4\%) GOLD C, and $38(36.2 \%)$ GOLD D. The characteristics of the subjects are given in Table 1 . The mean age was $56.99 \mathrm{y}$, and $89.5 \%$ of the subjects were male. Severity of air-flow limitation varied from mild to very severe.

A significant difference was found between the categories in terms of urinary albumin/creatinine ratio based on the new version of GOLD staging (A-D class) (Fig. 1) $(P<.001)$. There were significant differences in urinary albumin/creatinine ratio between the subjects in categories $\mathrm{A}$ and $\mathrm{B}(P=.001), \mathrm{A}$ and $\mathrm{C}(P=.001), \mathrm{A}$ and $\mathrm{D}$ $(P=.001), \mathrm{B}$ and $\mathrm{C}(P=.001)$, and $\mathrm{B}$ and $\mathrm{D}(P=.001)$ but not between $\mathrm{C}$ and $\mathrm{D}(P=.31)$. 


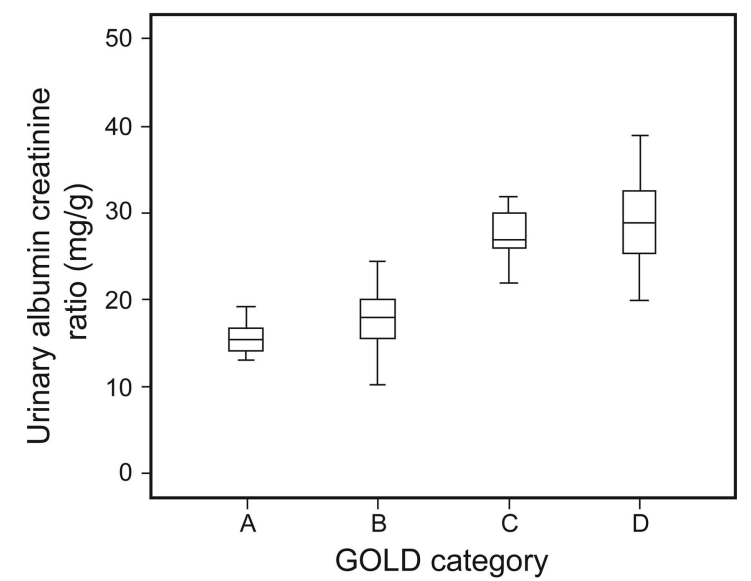

Fig. 1. Urinary albumin creatinine ratio of subjects grouped according to Global Initiative for Chronic Obstructive Lung Disease (GOLD) categories. Upper and lower borders of boxes represent the third and first quartiles, center lines denote the median, and whiskers show the 5th and 95th percentiles.

COPD subject subgroups were also compared in terms of urinary albumin/creatinine ratio based on $\mathrm{FEV}_{1}$ GOLD stages, $\mathrm{FEV}_{1}$ (median split, $<60 \%$ vs $\geq 60 \%$ ), COPD assessment test ( $<10$ vs $\geq 10$ ), and exacerbation history $(0-1$ vs $\geq 2$ ). Urinary albumin/creatinine ratio showed a significant difference, depending on the categories of each COPD parameter (Table 2). Furthermore, significant differences were also observed when subjects were grouped according to median split C-reactive protein $(\leq 4.6 \mathrm{mg} / \mathrm{L}$ vs $>4.6 \mathrm{mg} / \mathrm{L}), \mathrm{P}_{\mathrm{aO}_{2}}$ ( $\leq 65 \mathrm{~mm} \mathrm{Hg}$ vs $>65 \mathrm{~mm} \mathrm{Hg}), \mathrm{P}_{\mathrm{aCO}_{2}}(\leq 41 \mathrm{~mm} \mathrm{Hg}$ vs $>41 \mathrm{~mm} \mathrm{Hg}$ ), and arterial oxygen saturation ( $\leq 92 \%$ vs $>92 \%$ ) (Table 2).

In the Pearson correlation analysis performed, the urinary albumin/creatinine ratio was found to be significantly inversely correlated with $\mathrm{P}_{\mathrm{aO}_{2}}(\mathrm{r}=-0.60, P=.001)$, percent-of-predicted $\mathrm{FEV}_{1}(\mathrm{r}=-0.56, P=.001)$, and percent-of-predicted arterial oxygen saturation $(\mathrm{r}=-0.48$, $P=.001)$. There was a positive correlation between the urinary albumin/creatinine ratio and COPD assessment test scores $(\mathrm{r}=0.53, P=.001)$ (Table 3$)$. The urinary albumin/creatinine ratio value was increased as $\mathrm{FEV}_{1}$ and $\mathrm{P}_{\mathrm{aO}}$ were decreased, and the COPD assessment test score increased (Figs. 2-4).

In the logistic regression model, the urinary albu$\mathrm{min} /$ creatinine ratio was found to be significantly correlated with $\operatorname{FEV}_{1}(P=.046)$ and history of exacerbation $(P=.001)$. However, the urinary albumin/creatinine ratio did not show significant correlations with age, sex, C-reactive protein, body mass index, and smoking status (Table 4).

\section{Discussion}

The present study aimed to investigate the association of microalbuminuria with the new version of GOLD stag-
Table 2. Urinary Albumin/Creatine Ratio of Subjects in COPD Subgroups

\begin{tabular}{|c|c|c|c|}
\hline \multirow{2}{*}{ Variables } & \multicolumn{3}{|c|}{ UACR } \\
\hline & $n$ & Mean & $P$ \\
\hline $\mathrm{FEV}_{1}$ (GOLD stages) & & & .001 \\
\hline $1(\geq 80 \%)$ & 12 & $15.91 \pm 1.70$ & \\
\hline $2(50 \%-80 \%)$ & 57 & $19.26 \pm 5.69$ & \\
\hline $3(50 \%-30 \%)$ & 26 & $28.28 \pm 4.33$ & \\
\hline $4(<30 \%)$ & 10 & $33.1 \pm 6.46$ & \\
\hline $\mathrm{FEV}_{1}$ (median split) & & & .001 \\
\hline$<60$ & 51 & $25.44 \pm 8.26$ & \\
\hline$\geq 60$ & 54 & $19.59 \pm 5.30$ & \\
\hline CAT & & & .001 \\
\hline$<10$ & 41 & $18.83 \pm 6.11$ & \\
\hline$\geq 10$ & 64 & $24.74 \pm 7.39$ & \\
\hline Exacerbations & & & .001 \\
\hline $0-1$ & 55 & $16.52 \pm 3.21$ & \\
\hline$\geq 2$ & 50 & $28.94 \pm 4.97$ & \\
\hline BMI & & & .49 \\
\hline$\geq 30$ & 14 & $23.12 \pm 6.26$ & \\
\hline$<30$ & 91 & $22.33 \pm 7.66$ & \\
\hline C-reactive protein (median split) & & & .001 \\
\hline$\leq 4.6$ & 53 & $18.57 \pm 5.35$ & \\
\hline$>4.6$ & 52 & $26.37 \pm 7.29$ & \\
\hline $\mathrm{P}_{\mathrm{aO}_{2}}$ & & & .001 \\
\hline$\leq 65 \mathrm{~mm} \mathrm{Hg}$ & 63 & $25.85 \pm 7.16$ & \\
\hline$>65 \mathrm{~mm} \mathrm{Hg}$ & 42 & $17.30 \pm 4.36$ & \\
\hline $\mathrm{P}_{\mathrm{aCO}_{2}}$ & & & .01 \\
\hline$\leq 41 \mathrm{~mm} \mathrm{Hg}$ & 57 & $20.73 \pm 6.89$ & \\
\hline$>41 \mathrm{~mm} \mathrm{Hg}$ & 48 & $24.45 \pm 7.69$ & \\
\hline $\mathrm{pH}$ & & & .72 \\
\hline$\leq 7.45$ & 61 & $22.15 \pm 7.32$ & \\
\hline$>7.45$ & 44 & $22.82 \pm 7.74$ & \\
\hline$\%$ predicted $\mathrm{S}_{\mathrm{aO}_{2}}$ & & & .001 \\
\hline$\leq 92$ & 65 & $24.81 \pm 7.84$ & \\
\hline$>92$ & 40 & $18.56 \pm 4.80$ & \\
\hline $\begin{array}{l}\mathrm{UACR}=\text { urinary albumin/creatine ratio } \\
\mathrm{GOLD}=\text { Global Initiative for Chronic Obstru } \\
\mathrm{CAT}=\mathrm{COPD} \text { assessment test } \\
\mathrm{BMI}=\text { body mass index } \\
\mathrm{S}_{\mathrm{aO}_{2}}=\text { oxygen saturation }\end{array}$ & Lung & & \\
\hline
\end{tabular}

ing in subjects with COPD. The results of the study showed that urinary albumin/creatinine ratio was much higher in the subjects classified in the group with more symptoms and high future risk compared with the group with fewer symptoms and low future risk. The urinary albumin/creatinine ratio was determined to be statistically significantly different between the groups when classified based on $\mathrm{FEV}_{1}$, history of exacerbations and COPD assessment test scores.

Although there have been very few studies in the literature about microalbuminuria in subjects with COPD, there have been some that have reported the prevalence of microalbuminuria in such subjects. $7,10,16$ In one of these pre- 
Table 3. Results of Spearman Correlation Analysis on All Subjects Included in the Study

\begin{tabular}{lrc}
\hline \hline \multirow{2}{*}{ Variable } & \multicolumn{2}{c}{ Urinary Albumin/Creatine Ratio } \\
\cline { 2 - 3 } & \multicolumn{1}{c}{$\mathrm{r}$} & $P$ \\
\hline $\mathrm{BMI}$ & 0.14 & .13 \\
$\mathrm{Age}(\mathrm{y})$ & 0.29 & .002 \\
$\mathrm{P}_{\mathrm{aO}_{2}}$ & -0.60 & .001 \\
$\mathrm{P}_{\mathrm{aCO}_{2}}$ & 0.34 & .001 \\
$\mathrm{~S}_{\mathrm{aO}_{2}}$ & -0.48 & .001 \\
$\mathrm{CAT}$ & 0.53 & .001 \\
$\mathrm{Exacerbations}$ & 0.75 & .001 \\
$\mathrm{FEV}$ & -0.56 & .001 \\
$\mathrm{C}_{1}-$ reactive protein & 0.55 & .001 \\
& & \\
$\mathrm{BMI}=$ body mass index & & \\
$\mathrm{S}_{\mathrm{aO}}=$ oxygen saturation & & \\
CAT = COPD assessment test & & \\
\hline
\end{tabular}

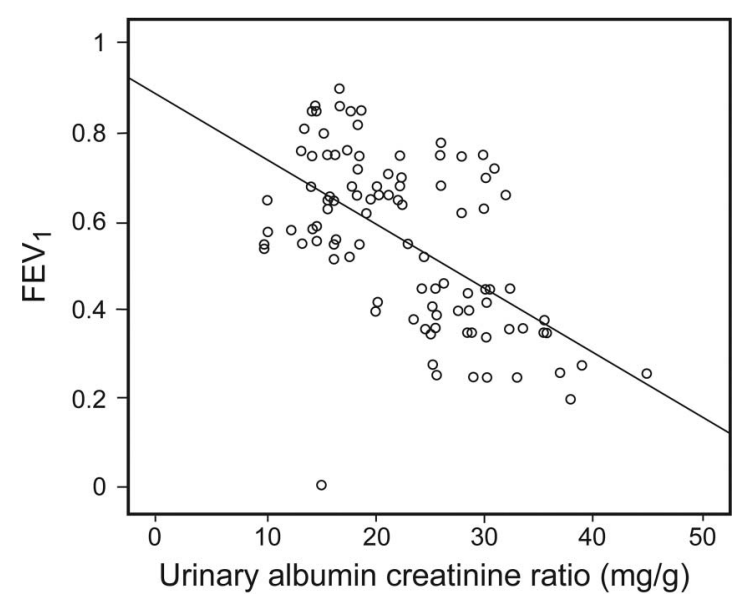

Fig. 2. Correlation of urinary albumin creatinine ratio and $F E V_{1}$ in subjects with COPD grouped according to Global Initiative for Chronic Obstructive Lung Disease categories $(P<.001)$.

vious studies, the microalbuminuria level was measured in 25 subjects during exacerbations. Of these subjects, $56 \%$ had microalbuminuria at the time of admission and $28 \%$ at discharge, whereas this rate was only $4 \%$ in the control group. In the same study, microalbuminuria was correlated with hypoxemia but not with the $\mathrm{FEV}_{1} \cdot{ }^{7}$ In another similar study that evaluated subjects during exacerbations, the authors reported that microalbuminuria was associated with the presence of respiratory failure. However, no spirometric measurements were performed in that study. ${ }^{10}$ In another study of 33 subjects with stable COPD, 26 subjects with exacerbation, and 16 healthy controls, the level of microalbuminuria was significantly increased only in the exacerbation group. However, the level of microalbuminuria in the stable COPD group was double that of the control subjects. ${ }^{16}$ These results indicate that microalbuminuria is common in COPD and seems to increase during

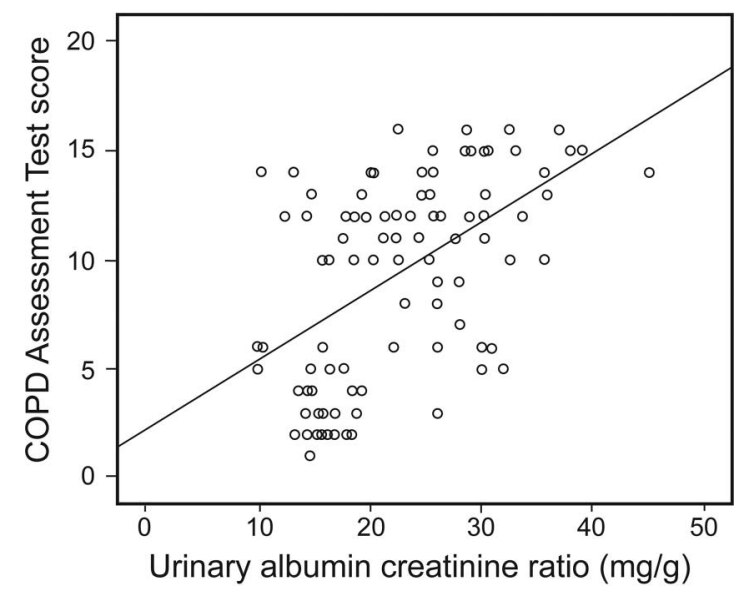

Fig. 3. Correlation of urinary albumin creatinine and COPD assessment test in subjects with COPD grouped according to Global Initiative for Chronic Obstructive Lung Disease categories $(P<.001)$.

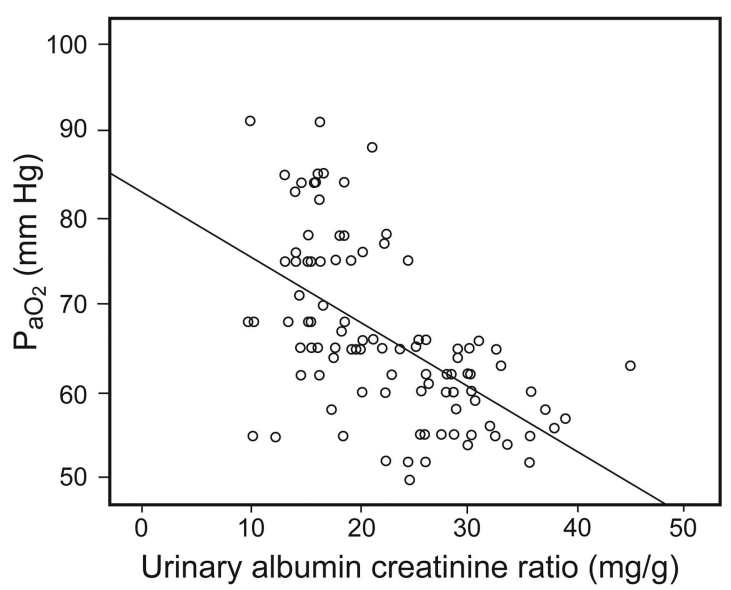

Fig. 4. Correlation of urinary albumin creatinine and $\mathrm{P}_{\mathrm{aO}_{2}}$ in subjects with COPD grouped according to Global Initiative for Chronic Obstructive Lung Disease categories $(P<.001)$.

exacerbations. However, in one published report, Casanova et $\mathrm{al}^{17}$ demonstrated that the incidence of microalbuminuria was high in subjects with stable COPD and was associated with hypoxemia independently of the other cardiovascular risk factors. Similar results were obtained by Bulcun et al, ${ }^{18}$ where microalbuminuria was also associated with the severity of disease. Likewise, in the present study, microalbuminuria was identified in 57 (54.3\%) of the subjects in the study group. Subjects with COPD in all GOLD categories were included in the current study, and the urinary albumin/creatinine ratio values were found to be higher in groups $\mathrm{C}$ and $\mathrm{D}$ than in groups $\mathrm{A}$ and $\mathrm{B}$.

Body mass index decreases in patients with severe COPD. Morbidity and mortality increase as the body mass index value decreases, particularly in elderly and hypoxic subjects. ${ }^{19}$ Although a limited number of studies have found 


\section{Microalbuminuria and GOLD Stage in Subjects With COPD}

Table 4. Risk Factors for Cardiovascular Diseases in Subjects With COPD: Multivariate Analysis

\begin{tabular}{lrll}
\hline \hline \multicolumn{1}{c}{ Risk Factors } & Odds Ratio & \multicolumn{1}{c}{$95 \%$ CI } & $P$ \\
\hline Age $(\mathrm{y})$ & -0.06 & -0.14 to 0.009 & .08 \\
Male sex & -2.03 & -4.70 to 0.63 & .13 \\
C-reactive protein $(\mathrm{mg} / \mathrm{dl})$ & 0.02 & -0.31 to 0.31 & .89 \\
BMI $\left(\mathrm{kg} / \mathrm{m}^{2}\right)$ & 0.25 & -2.10 to 2.61 & .83 \\
FEV $_{1}$ & -0.06 & -0.12 to 0.001 & .041 \\
Exacerbations & -11.48 & -13.93 to 9.02 & .001 \\
Smoking history & 0.04 & -0.02 to 0.11 & .18 \\
& & & \\
BMI = body mass index & & & \\
\hline
\end{tabular}

an association between urinary albumin excretion rate and obesity, other studies have found no significant correlation. ${ }^{17,20-22}$ Similarly, in the present study, no such a correlation was observed between the study groups.

Smoking decreases renal blood flow, glomerular filtration rate, and filtration fraction in healthy persons, all of which increase renovascular resistance, resulting in thickening of the renal arterioles and causing renal blood flow to be functionally disrupted. Consequently, the filtration rate is decreased in persons with a normal glomerular filtration rate. However, small repeated transient renal hypoperfusion episodes may damage some glomeruli and eventually lead to structural changes, such as hyperfiltration and hypertrophy in remnant glomeruli, causing increased glomerular filtration rate and albumin excretion. ${ }^{23}$ It has been argued that increased hypoxic stimulation in endothelial cells could cause endothelial dysfunction, resulting in higher microalbuminuria in smokers. ${ }^{20}$ Although some studies have found a significant correlation between microalbuminuria and smoking history in subjects with COPD, others have observed no such association.9,22,24 In the present study, no correlation was determined between microalbuminuria and smoking history.

Increased sympathetic activity due to hypoxemia can also play a role in capillary endothelial permeability, causing proteinuria through increased capillary permeability. This is not influenced by altered renal tubular function, increased blood pressure, and renal filtration rate. ${ }^{25}$ A study performed on 102 subjects with similar serum protein levels demonstrated a significant correlation between decreased $\mathrm{P}_{\mathrm{aO}_{2}}$ level and high urinary protein excretion. ${ }^{11}$ Vasoconstriction resulting from hypoxemia and respiratory acidosis-induced glomerular albumin filtration are increased in patients with cor pulmonale with sleep apnea syndrome. This mechanism may be responsible for the short-term proteinuria seen in subjects with COPD. ${ }^{26}$ In a study by Casanova et al, ${ }^{17}$ most COPD subjects with microalbuminuria were found to have hypoxemia, with the highest values $(>50 \mathrm{mg} / \mathrm{g})$ of microalbuminuria observed in subjects with a $\mathrm{P}_{\mathrm{aO}_{2}}$ level of $<70 \mathrm{~mm} \mathrm{Hg}$. Likewise, in the present study, the urinary albumin/creatinine ratio values of subjects were found to be much higher when the subjects were grouped based on median split $\mathrm{P}_{\mathrm{aO}_{2}}$ levels ( $\leq 65 \mathrm{~mm} \mathrm{Hg}$ vs $>65 \mathrm{~mm} \mathrm{Hg}$ ). Nevertheless, some patients with hypoxemia may not present evidence of microalbuminuria, suggesting that other factors, including genetic susceptibility to oxidative stress, may also be implicated. ${ }^{27}$

Again in another study, COPD subjects with microalbuminuria were found to be statistically significantly more hypoxic and more hypercapnic compared with COPD subjects without microalbuminuria. As a result of that study, $\mathrm{P}_{\mathrm{aO}_{2}}$, which showed a negative correlation with microalbuminuria, was determined to be the most important predictive factor. ${ }^{28}$ In a study by Kömürcuoğlu et al, ${ }^{10}$ a negative relationship was determined between microalbuminuria identified in subjects with COPD and levels of $\mathrm{P}_{\mathrm{aO}_{2}}$ and arterial oxygen saturation, although no significant correlation between microalbuminuria and levels of $\mathrm{pH}$ and $\mathrm{P}_{\mathrm{aCO}_{2}}$ was observed. It was suggested in that study that microalbuminuria could have developed as a result of increased glomerular filtration due to increased hypoxemia, eventually developing protein leakage. ${ }^{10}$ In the present study, a significant inverse correlation was determined between urinary albumin/creatinine ratio and $\mathrm{P}_{\mathrm{aO}}$, and a positive correlation was found between urinary albumin/creatinine ratio and $\mathrm{P}_{\mathrm{aCO}}$.

In a study by Celli et al, ${ }^{29}$ most COPD subjects with microalbuminuria were GOLD stage III and IV, whereas those with no microalbuminuria were GOLD stage I and II; the difference was statistically significant. This could possibly be explained by impaired lung function, including COPD, which has been associated with increased systemic arterial stiffness. Given the relationship between abnormal lung function and arterial stiffness, an increase in arterial stiffness should lead to increased kinetic energy transmission to the distal microcirculation, thus resulting in microvascular damage. ${ }^{29}$ Emerging evidence demonstrates that the degree of air-flow limitation is poorly predictive of dyspnea and quality of life. ${ }^{30}$ Therefore, the classification of severity groups, as described by the GOLD committee, has moved away from a linear approach based only on degree of airway limitation to a 2-dimensional evaluation that includes both the risk and symptom assessment. ${ }^{12}$ In the present study, subjects with COPD were categorized into A, B, C, and D groups, combining symptom assessment by COPD assessment test scores, air-flow limitation, and risk of exacerbation. The urinary albumin/creatinine ratio values were found to be higher in groups $C$ and $D$ than in groups $\mathrm{A}$ and $\mathrm{B}$. In the study by Celli et al, ${ }^{29}$ whereas Modified Medical Research Council dyspnea scale scores were 3 and 4 in COPD subjects with microalbuminuria, the scores were 1 and 2 in COPD subjects without microalbuminuria. This was considered to be due to the increased endothelial damage caused by hypoxia in sub- 


\section{Microalbuminuria and GOLD Stage in Subjects With COPD}

jects with grade III and IV dyspnea leading to microalbuminuria. In the current study, symptoms were assessed with COPD assessment test scores, and the urinary albu$\mathrm{min} /$ creatinine ratio levels were found to be much higher when the subjects were grouped based on median split COPD assessment test $(<10$ vs $\geq 10)$. However, when GOLD C and D subjects with a $\mathrm{FEV}_{1}$ value $<50 \%$ were evaluated according to the symptoms, no significant correlation was found.

C-reactive protein is an acute phase reactant, the level of which rises in response to tissue injury and/or inflammation. In previous studies, it has been thought that microalbuminuria, which is an inflammatory marker of vascular endothelial dysfunction, could be associated with C-reactive protein. ${ }^{20,31,32} \mathrm{In}$ a study by Stuveling et al, ${ }^{20} \mathrm{C}$-reactive protein changes were investigated in a study group with no diabetes hypertension and with diabetes. The association between microalbuminuria and blood pressure, and elevated urinary albumin/creatinine ratio was found to be correlated with inflammation. ${ }^{20}$ In the present study, the urinary albumin/creatinine ratio was found to be significantly higher in the subject group with $\mathrm{C}$-reactive protein $>4.6 \mathrm{mg} / \mathrm{L}$.

The present study has several limitations. First, the relatively small sample size of the study may not be representative for subjects with COPD. Moreover, all subjects were in a stable period, and therefore comparisons could not be made of urinary albumin/creatinine ratio in both the exacerbation and stable periods. In addition, since the main objective of this study was to investigate the microalbuminuria relationship in COPD subgroups, no control group was included. There is a need for further studies with larger sample sizes to confirm these findings. Furthermore, the cross-sectional structure of the data did not allow causal links to be established. Another limitation was that, because the number of female subjects was limited, possible sex differences in microalbuminuria could not be evaluated.

\section{Conclusions}

The results of our study indicate a strong correlation between microalbuminuria and the new version of GOLD stages. Microalbuminuria is evaluated as a risk factor for cardiovascular diseases. Because the diagnosis of microalbuminuria is simple, inexpensive, and noninvasive, it can be evaluated routinely in COPD cases, especially those with many symptoms who are at high risk, in terms of cardiovascular morbidity and mortality. Further studies are warranted to determine the correlation between microalbuminuria and severity of disease, including successful treatment and longitudinal subject processes, and COPD.

\section{REFERENCES}

1. Mannino DM, Buist AS. Global burden of COPD: risk factors, prevalence, and future trends. Lancet 2007;370(9589):765-773.

2. Ghoorah K, De Soyza A, Kunadian V. Increased cardiovascular risk in patients with chronic obstructive pulmonary disease and the potential mechanisms linking the two conditions: a review. Cardiol Rev 2013;21(4):196-202.

3. Diercks GF, van Boven AJ, Hillege JL, de Jong PE, Rouleau JL, van Gilst WH. The importance of microalbuminuria as a cardiovascular risk indicator: Areview. Can J Cardiol 2002;18(5):525-535.

4. Weir MR. Microalbuminuria and cardiovascular disease. Clin J Am Soc Nephrol 2007;2(3):581-590.

5. Papaioannou GI, Seip RL, Grey NJ, Katten D, Taylor A, Inzucchi $\mathrm{SE}$, et al. Brachial artery reactivity in asymptomatic patients with type 2 diabetes mellitus and microalbuminuria. Am J Cardiol 2004; 94(3):294-299.

6. Mulè $\mathrm{G}$, Cottone $\mathrm{S}$, Vadalà $\mathrm{A}$, Volpe $\mathrm{V}$, Mezzatesta $\mathrm{G}$, Mongiovì R, et al. Relationship between albumin excretion rate and aortic stiffness in untreated essential hypertensive patients. J Intern Med 2004; 256(1):22-29.

7. Ibsen H, Olsen MH, Wachtell K, Borch-Johnsen K, Lindholm LH, Mogensen CE, et al. Reduction in albuminuria translates to reduction in cardiovascular events in hypertensive patients: losartan intervention for end point reduction in hypertension study. Hypertension 2005;45(2):198-202.

8. Barr RG, Mesia-Vela S, Austin JH, Basner RC, Keller BM, Reeves AP, et al. Impaired flow mediated dilation is associated with low pulmonary function and emphysema in ex-smokers: the Emphysema and Cancer Action Project (EMCAP) Study. Am J Respir Crit Care Med 2007;176(12):1200-1207.

9. Polatli M, Cakir A, Cildag O, Bolaman AZ, Yenisey C, Yenicerioglu Y. Microalbuminuria, von Willebrand factor and fibrinogen levels as markers of the severity in COPD exacerbation. J Thromb Thrombolysis 2008;26(2):97-102.

10. Kömürcuoğlu A, Kalenci S, Kalenci D, Kömürcüoğlu B, Tibet G. Microalbuminuria in chronic obstructive pulmonary disease. Monaldi Arch Chest Dis 2003;59(4):269-272.

11. Gogo A, Ciaccia A, Legorini C, Grimaldi A, Milani G. Proteinuria in COPD patients with and without respiratory failure. Chest 2003; 123(2):652-653; author reply 653

12. Global Initiative for Chronic Obstructive Lung Disease. Global strategy for the diagnosis, management, and prevention of chronic obstructive pulmonary disease. 2016. http://goldcopd.org/globalstrategy-diagnosis-management-prevention-copd-2016.

13. Bestall JC, Paul EA, Garrod R, Garnham R, Jones PW, Wedzicha JA. Usefulness of the Medical Research Council (MRC) dyspnoea scale as a measure of disability in patients with chronic obstructive pulmonary disease. Thorax 1999;54(7):581-586.

14. Jones PW, Harding G, Berry P, Wiklund I, Chen WH, Kline Leidy N. Development and first validation of the COPD Assessment Test. Eur Respir J 2009;34(3):648-654.

15. Brusasco V, Crapo R, Viegi G, American Thoracic Society, European Respiratory Society. Coming together: the ATS/ERS consensus on clinical pulmonary function testing. Eur Respir J. 2005;26(1):1-2.

16. Wachtell K, Ibsen H, Olsen MH, Borch-Johnsen K, Lindholm LH, Mogensen CE, et al. Albuminuria and cardiovascular risk in hypertensive patients with left ventricular hypertrophy: the LIFE Study. Ann Intern Med 2003;139(11):901-906.

17. Casanova C, de Torres JP, Navarro J, Aguirre-Jaíme A, Toledo P, Cordoba E, et al. Microalbuminuria and hypoxia in patients with chronic obstructive pulmonary disease. Am J Respir Crit Care Med 2010;182(8):1004-1010.

18. Bulcun E, Ekici M, Ekici A, Kisa U. Microalbuminuria in chronic obstructive pulmonary disease. COPD 2013;10(2):186-192. 


\section{Microalbuminuria and GOLD Stage in Subjects With COPD}

19. Phelps DT, Ferro TJ, Higgins PJ, Shankar R, Parker DM, Johnson A. TNF- $\alpha$ induces peroxynitrite-mediated depletion of lung endothelial glutathione via protein kinase C. Am J Physiol 1995;269(4 Pt 1): L551-L559.

20. Stuveling EM, Bakker SJ, Hillege HL, Burgerhof JG, de Jong PE, Gans RO, et al. C reactive protein modifies the relationship between blood pressure and microalbuminuria. Hypertension 2004;43(4):791796.

21. Thoenes M, Reil JC, Khan BV, Bramlage P, Volpe M, Kirch W, Böhm M. Abdominal obesity is associated with microalbuminuria and an elevated cardiovascular risk profile in patients with hypertension. Vasc Health Risk Manag 2009;5(4):577-585.

22. Kaysoydu E, Arslan S, Yıldiz G, Candan F. Factors related to microalbuminuria in patients with chronic obstructive pulmonary disease. Adv Clin Exp Med 2014;23(5):749-755.

23. Pinto-Sietsma SJ, Mulder J, Janssen WM, Hillege HL, de Zeeuw D, de Jong PE. Smoking is related to albuminuria and abnormal renal function in nondiabetic persons. Ann Intern Med 2000;133(8):585591.

24. Metoki H, Ohkubo T, Kikuya M, Asayama K, Obara T, Hashimoto $\mathrm{J}$, et al. Prognostic significance for stroke of a morning pressor surge and a nocturnal blood pressure decline: the Ohasama study. Hypertension 2006;47(2):149-154.

25. Hansen JM, Olsen NV, Feldt-Rasmussen B, Kanstrup IL, Déchaux M, Dubray C, Richalet JP. Albuminuria and over all capillary per- meability of albumin in acute altitude hypoxia. J Appl Physiol 1994; 76(5):1922-1927.

26. Sklar AH, Chaudhary BA. Reversible proteinuria in obstructive sleep apnea syndrome. Arch Intern Med 1988;148(1):87-89.

27. Shin KK, Jang Y, Koh SJ, Chae JS, Kim OY, Park S, et al. Influence of the IL-6-572C $>\mathrm{G}$ polymorphism on inflammatory markers according to cigarette smoking in Korean healthy men. Cytokine 2007; 39(2):116-122.

28. Mehmood K, Sofi FA. Microalbuminuria and hypoxemia in patients with COPD. J Pulm Respir Med 2015;5:280. doi: 10.4172/2161105X.1000280.

29. Celli BR, Cote CG, Marin JM, Casanova C, Montes de Oca M, Mendez RA, et al. The body mass index, airflow obstruction, dyspnea, exercise performance (BODE) index in chronic obstructive pulmonary disease. N Engl J Med 2004;350(10):1005-1012.

30. Garcia-Aymerich J, Serra Pons I, Mannino DM, Maas AK, Miller DP, Davis KJ. Lung function impairment, COPD hospitalisations and subsequent mortality Thorax 2011;66(7):585-590.

31. Sin DD, Anthonisen NR, Soriano JB, Agusti AG. Mortality in COPD: role of comorbidities. Eur Respir J 2006;28(6):1245-1257.

32. Forsblom CM, Groop PH, Ekstrand A, Tötterman KJ, Sane T, Saloranta C, Groop L. Predictors of progression from normoalbuminuria to microalbuminuria in NIDDM. Diabetes Care 1998;21(11): 1932-1938. 